\section{SIV grows unchanged in human cells}

SIR-Adaption of simian immunodeficiency viruses (SIV) to growth in human cells has been claimed to result in the mutation and selection of virus substrains ${ }^{1}$. Specifically, selection of a premature termination codon in the cytoplasmic domain of the transmembrane protein (TMP) encoded by the env gene has been noted and TMP truncation correlated with improved growth in human cells ${ }^{1-4}$.

By contrast, we report here that at least four different isolates of SIV $_{\text {agm }}$ from naturally infected African green monkeys (AGM) in our colony consistently express a full-length transmembrane protein with the apparent relative molecular mass of 45,000 (Fig. 1, lanes 2, 3, 5) (ref. 5). These isolates are variants which are easily distinguishable by restriction enzyme mapping and nucleotide sequence divergence. Moreover, a related immunodeficiency

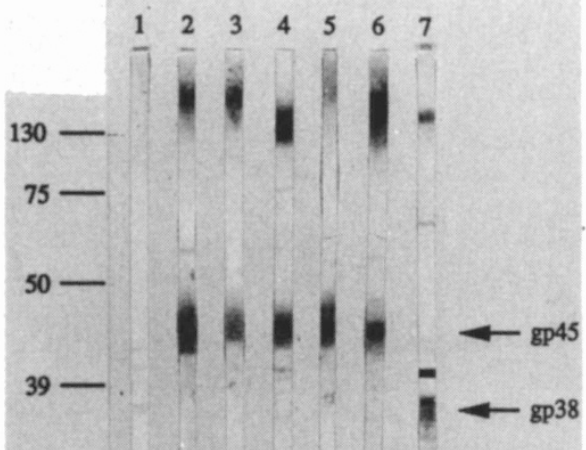

27

17

FIG. 1 Western blot analysis of SIV agmabm $_{\text {anti- }}$ gens. Lanes 1-3: SIV ${ }_{\text {agm38 }}$ antigen; lane 4: SIV $_{\text {abm }}$ antigen; lane 5: SIV ${ }_{\text {agm3 }}$ wild type antigen; lane 6: molecularly cloned and transfected SIV agm3 $_{\text {i lane 7: SIV }}$ TYm TYO-1 antigen. SIV $_{\text {agm }}$ antigen in lanes 2,6 and 7 were prepared after short-term culture of 4-8 weeks. SIV $_{\text {abm }}$ antigen was prepared after 8-months culture. SIV agm $_{\text {antigen in lanes } 3 \text { and } 5 \text { were }}$ prepared after long-term culture of more than a year. Viruses were cultured in Molt $4 / 8$ cells. Relative molecular masses (left), in thousands. virus $\left(\mathrm{SIV}_{\mathrm{abm}}\right)$ isolated from an African blue monkey caught in the wild also continues to express a full-length gp45 TMP after prolonged growth in human cells (Fig. 1, lane 4)

All our SIV strains have been isolated by cocultivation of phytohaemagglutinin (PHA)-stimulated monkey peripheral blood lymphocytes with human Molt4/8 T-lymphoma cells. For example, after short-term cultivation of 3 weeks, a fulllength molecular clone of wild-type SIV $_{\text {agm3 }}$ (see Fig. 1, lane 5) was isolated and biologically and genetically characterized ${ }^{6,7}$. The clone was found to be replication-competent in vitro and in vivo. No premature stop codon in env or in any other gene was detected after complete sequence analysis. Western blot analysis of wild-type and molecularly cloned virus after transfection in Molt4/8 cells confirmed the expression of gp45 (Fig. 1, lanes 5 and 6 , respectively). These results demonstrate the presence of wild-type viruses with full-length TMPs in their natural host and their successful replication in short-term culture.

Full-length TMPs of our virus isolates were detected even after long-term culture. We were able to show by western blot analysis, the presence of untruncated transmembrane proteins in all SIV $_{\text {agm/abm }}$ isolates even after tissue culture for more than a year (Fig. 1).

Two full-length molecular clones of SIV $_{\text {agm }}$ have been described ${ }^{7.8}$. One, termed SIV TYm $_{\text {TY }} 1$, contains a stop codon at a position corresponding to codon 776 in the molecular clone $\mathrm{SIV}_{\text {agm3 }}$ (Fig. 1, lane 7 and Fig. 2) (5, $11^{\text {. These and }}$ all other SIV $_{\text {agm }}$ isolates $^{9-11}$ are usually grown and replicate well only in Molt4/8 restricted host range, replicating to low titres in CEM and HUT-78 cells and not at all in many other human CD4+ lymphoma lines ${ }^{5,10}$. Thus, regardless of the unchanged length of their TMPs, replication of $\mathrm{SIV}_{\mathrm{agm}}$ in human cells is virtually restricted to the Molt4/8 lymphoma line. Infection of seronegative African green monkeys is readily achieved with cell-free preparations of $\mathrm{SIV}_{\text {agm }}$ with or without cells. Otherwise, these strains have a very truncated TMPs ${ }^{5,6,10}$

All presently available data support the hypothesis that selection against virus substrains predominant in vivo occurs only in cell lines that restrict their replication in vitro, as observed with SIV Sn $_{\text {mac }}$ in several human cell lines. Therefore, per-

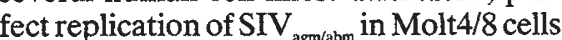
or HIV-1 and HIV-2 in human cells lines would impose no drive for selection of adapted mutants. It is easily conceivable that what is observed in vitro may also happen in vivo. In other words, variants with full-length or truncated TMP may be distributed in an organ-specific manner depending on their potential to replicate in a specific cell type. The studies with $\mathrm{SIV}_{\mathrm{mac}}{ }^{1-4}$ and $\mathrm{SIV}_{\mathrm{agm}}{ }_{5.8}$ suggest that genetic information downstream of the premature TMP stop codon may contain a negative regulatory element for HIV/SIV replication in certain host cells.

ALBRECHT WERNER MICHAEL BAIER KLAUS CICHUTEK REINHARD KURTH

Paul-Ehrlich-Institute,

Paul-Ehrlich-Strasse 51-59,

D-6070 Langen 1/Frankfurt, FRG

WALLY BECKER

Department of Medical Virology,

Faculty of Medicine,

University of Stellenbosch,

Tygerberg (7505),

\section{Republic of South Africa}

1. Hirsch, V.M. et al. Nature 341, 573-574 (1989)

2. Kodama, Tet al. J. Virol. 63, 4709-4714 (1989)

3. Chakrabarti, L., Emerman, M., Tiollais, P. \& Sonigo, P. J. Virol. 63, 4395-4403 (1989)

4. Meyerhans, A. et al. Cell 58, 901-910 (1989)

5. Kraus, G. et al. Proc. natn. Acad. Sci. U.S.A. 86, 2892 2896 (1989).

6. Baier, M. et al. J. Virol. 63, 5119-5123 (1989)

7. Baier, M., Garber, C., Müller, C., Cichutek, K. \& Kurth, R. Virology (in the press)

8. Fukasawa, M. et al. Nature 333, 457-461 (1988)

9. Fultz, P.N. et al. J. clin. Microbiol. 83, 5286-5290 (1986)

10. Ohta, Y. et al. Int. J. Cancer 41, 115-122 (1988) 11. Kodama, T. et al. J. Virol. 62, 4782-4785 (1988).

\section{CF screening}

SIR-Ten Kate (Nature 342, 131; 1989) suggests that carrier screening for cystic fibrosis (CF) should be postponed until 96 per cent of the possible mutations have been detected, on the grounds that so long as a substantial proportion of $\mathrm{CF}$ is not associated with the now-identifiable mutation $\Delta F_{508}$, the risk for a couple only one of which is identified as a carrier would still be greater (at 1 in 300) than for unscreened couples ( 1 in 2,500). We are not so sure.

First, the proportion of CF associated with the $\Delta F_{508}$ mutation is likely to be greater in Northern Europe than in North America. Our first impression, after screening 220 chromosomes, is that the proportion of CF caused by this mutation in Britain is more like 80 per cent than the 67 per cent reported by Kerem et al. (Science 245, 1073-1080; 1989). If the CF
FIG. 2 Sequence comparison between transmembrane proteins of molecularly cloned SIV agm $3_{3}$

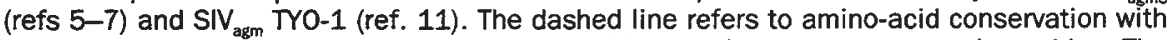
amino-acid numbering corresponding to the positions in the env-precursor polypeptides. The premature termination codon of SIV $_{\text {agm }}$ TYO-1 is indicated by the asterisk. 